\title{
Hot EVs - how temperature affects extracellular vesicles
}

Eilien Schulz ${ }^{1,2}$, Anna Karagianni ${ }^{1}$, Marcus Koch ${ }^{3}$, Gregor Fuhrmann ${ }^{1,2 *}$

${ }^{1}$ Biogenic Nanotherapeutics Group (BION), Helmholtz Centre for Infection Research (HZI), Helmholtz Institute for Pharmaceutical Research Saarland (HIPS), Campus E8.1, Saarbrücken 66123, Germany

${ }^{2}$ Department of Pharmacy, Saarland University, Campus E8.1, Saarbrücken 66123, Germany

${ }^{3}$ INM - Leibniz Institute for New Materials, Campus D2.2, Saarbrücken 66123, Germany

*Corresponding author, phone: +49 68198806 1500, Email: gregor.fuhrmann@helmholtz-hzi.de

ORCID IDs: Eilien Schulz: 0000-0002-9769-8980, Anna Karagianni: 0000-0002-0831-1247, Gregor Fuhrmann: 0000-0002-6688-5126

Keywords: extracellular vesicles, outer membrane vesicles, lymphoblastoid cells, myxobacteria, drug carriers, flow cytometry, heat stability, autoclaving 
In recent years, extracellular vesicles (EVs) and outer membrane vesicles (OMVs) have become an extensive and diverse field of research. They hold potential as diagnostic markers, therapeutics and for fundamental biological understanding. Despite ongoing studies, numerous information regarding function, content and stability of EVs remains unclear. If EVs and OMVs ought to be used as therapeutics and in clinical environments, their stability is one of the most important factors to be considered. Especially for formulation development, EVs and OMVs need to be stable at higher temperatures. To the best of our knowledge, very little work has been published regarding heat stability of neither EVs nor OMVs. In the present study, we investigated B lymphoblastoid cellderived EVs and OMVs derived from myxobacterial species Sorangiineae as model vesicles. We exposed the vesicles to $37^{\circ} \mathrm{C}, 50^{\circ} \mathrm{C}, 70^{\circ} \mathrm{C}$ and $100^{\circ} \mathrm{C}$ for $1 \mathrm{~h}, 6 \mathrm{~h}$ and $24 \mathrm{~h}$, and also autoclaved them. Physico-chemical analysis such as size, particle concentration and protein concentration showed interestingly minor alterations, particularly at $37^{\circ} \mathrm{C}$. Flow cytometry analysis emphasised these results suggesting that after heat impact, EVs and OMVs were still able to be taken up by macrophage-like dTHP-1 cells. These data indicate that both mammalian and bacterial vesicles show intrinsic stability at physiological temperature. Our findings are important to consider for vesicle formulation and for advanced bioengineering approaches. 


\section{Introduction}

Outer membrane vesicles (OMVs) were first mentioned 50 years ago in 1967, as Chatterjee et al detected particles in proximity to Vibrio cholera membranes in electron microscopy images (1). A few years later, in 1983 Pan et al. were the first ones to observe extracellular vesicles (EVs), while they monitored a transferrin receptor in sheep (2). Since then, this area of research has expanded extensively. Both, EVs and OMVs are nano-sized phospholipid bilayered assemblies and serve as transport vehicles for cell-cell communication (3). Their structure and surface is, in most cases, comparable to their cellular origin and consists of receptors, proteins or for OMVs lipopolysaccharides $(4,5)$. Contents may vary, but generally imply nucleic acid, proteins and secondary metabolites, such as toxins or compounds that are often unique to their origin (4-6). EVs have been isolated from a large variety of cells derived from the immune system, different tissues or the nervous system (3). OMVs, on the other hand have been isolated from almost all known gramnegative bacteria (7). Both, EVs and OMVs hold potential for the development of new therapeutics. They have already been applied in tissue repair, neurodegenerative disorders and cancer therapy (8). For example, EVs derived from mesenchymal stem cells have previously reached clinical trials as novel therapeutics for functional recovery after ischemic strokes (9). OMVs, on the other hand have been studied for vaccination, as drug delivery systems against cancer (10) or infections (11). Different routes of EV application have been established, either as intravenous suspensions or incorporated into hydrogels, for example for enzyme prodrug therapy $(12,13)$. Although many protocols have been established concerning vesicle isolation, the temperature stability of EVs and OMVs has not been studied comprehensively. Some publications analysed storage conditions for EV suspensions, while we and others have recently introduced a freeze-drying method using cryo-protectants (14-16). To our knowledge, very little is known to date concerning the stability of EVs and OMVs at increasing temperatures. Lee et al. studied the stability of EVs from Kaposi's sarcoma-associated herpesvirusinfected human endothelial cells and found that even after 4 days the particle concentration of samples incubated at $37^{\circ} \mathrm{C}$ did not alter (17). Moreover, Cheng et al determined the particle concentration of EVs at $37^{\circ} \mathrm{C}$ and at $60{ }^{\circ} \mathrm{C}$, resulting only in minor physical changes (18). However, it is essential to estimate the heat stability of EVs and OMVs in a more comprehensive manner, as it will help to evaluate their clinical and pharmaceutical applicability. In terms of pharmaceutical applicability, heat will also play a role during spray drying (19) or in the chemical modification to attach targeting moieties (20). In addition, to understand the biological role of EVs, higher temperatures could be necessary. As extracellular vesicles are often comprised of phospholipids, such as phosphatidylcholine, sphingomyelin and phosphatidylserine, they are similar in structure compared to liposomes (21). Heat-induced fusion of EVs with liposomes may also be beneficial to form new biocompatible nanocarriers (22). For intravenous injection, EVs need to be sterile as an aseptic production is not always possible. Sterilisation methods such as filtration may result in a loss of sample, leading to concentration issues (23). Pressurised saturated steam sterilisation, autoclaving may be convenient and quick, but potentially harsh method to obtain sterile vesicles for clinical applications.

Here, we used EVs derived from B lymphoblastoid cells (RO cells). They are a well-defined and commercially available cell line obtained from a patient with severe combined immunodeficiency, not expressing MHC class II complexes $(24,25)$. Thus, RO cell derived EVs may be low in immunogenicity. The cells can be grown in suspension and, therefore can be easily cultivated even in large quantities. We also established a method to cultivate RO cells in a low space consuming manner. As a second model vesicle we studied OMVs derived from the myxobacterial strain SBSr073. 
Myxobacteria are gram-negative, soil living bacteria, that are producer of a large variety of secondary metabolites (26). We recently showed that SBSr073 OMVs are non-toxic to human cells and have the potential to be further developed as a drug carrier system (11). As myxobacteria are found in various environments including deserts (27), we hypothesised that the OMVs they produce may be more resistant to high temperatures compared to human $\mathrm{EVs}$, which are adapted to a body temperature of $37^{\circ} \mathrm{C}$.

\section{Materials and Methods}

\subsection{Cell culture}

B lymphoblastoid cells (RO cells) (DSMZ, ACC 452, Braunschweig, Germany) were cultured in T75 flasks with an initial seeding density of $0.75^{*} 10^{6}$ cells $/ \mathrm{mL}$. After thawing cells, they were grown in RPMI (Gibco) with $15 \%(\mathrm{v} / \mathrm{v}$ ) foetal calve serum (FCS) (25). Before EV isolation, RPMI with $10 \%(\mathrm{v} / \mathrm{v})$ insulin-transferrin-selenium-ethanolamine (Thermo Fischer) was used. Cultures started with a volume of $45 \mathrm{~mL}$ in an upright position. After 3 days, $25 \mathrm{~mL}$ supernatant was removed and replaced with $50 \mathrm{~mL}$ fresh medium. Another subsequent 4 days later, $50 \mathrm{~mL}$ supernatant was removed for $\mathrm{EV}$ isolation. Supernatants were stored at $-80^{\circ} \mathrm{C}$ up to 2 months. Cells were used until passage 40 . THP-1 cells were cultivated in RPMI with $10 \%$ (v/v) FCS. Alternating, cells were seeded with an initial density of 2 or 3 million cells and cultivated for 3 or 4 days.

\subsection{Microbial culture}

SBSr073 myxobacteria (kindly provided by Rolf Müller, Department of Microbial Natural Products, Helmholtz Institute for Pharmaceutical Research, Saarbrücken) were cultivated as described previously (11), in 2 SWT medium $(0.3 \%(\mathrm{~m} / \mathrm{v})$ bacto tryptone, $0.1 \%(\mathrm{~m} / \mathrm{v})$ soytone, $0.2 \%(\mathrm{~m} / \mathrm{v})$ glucose, $0.2 \%(\mathrm{~m} / \mathrm{v})$ soluble starch, $0.1 \%(\mathrm{~m} / \mathrm{v})$ maltose monohydrate, $0.2 \%(\mathrm{~m} / \mathrm{v})$ cellobiose, $0.05 \%$ $(\mathrm{m} / \mathrm{v}) \mathrm{CaCl}_{2} * 2 \mathrm{H}_{2} \mathrm{O}, 0.1 \%(\mathrm{~m} / \mathrm{v}) \mathrm{MgSO}_{4} * 7 \mathrm{H}_{2} \mathrm{O}$ and $10 \mathrm{mM} \mathrm{HEPES}, \mathrm{pH} 7.0$ adjusted with $\left.\mathrm{KOH}\right)$. The bacterial suspension was cultivated at $30^{\circ} \mathrm{C}$ and shaken at $180 \mathrm{rpm}$ (Ecotron, Infors $\mathrm{HT}$, Bottmingen, Switzerland) for one week until OMV isolation. As this strain forms aggregates, it was not possible to determine a growth curve based neither on optical density measurements, nor on colony forming unit counting (11). OMVs were isolated from cultures cultivated until passage 6.

\subsection{Isolation and purification of EVs and OMVs}

Fifty millilitres of RO supernatant were first centrifuged at $300 \times \mathrm{g}$ for 8 min to remove cells. Forty millilitre were then transferred to a new tube and centrifuged at 9,500 $\times \mathrm{g}$ for $15 \mathrm{~min}$. SBSr073 supernatant was first centrifuged at $9,500 \times \mathrm{g}$ for $10 \mathrm{~min}$ to remove bacteria (28). Forty millilitre of this supernatant were centrifuged, at $9,500 \times \mathrm{g}$ for $15 \mathrm{~min}$. Both samples were then ultracentrifuged at $100,000 \times \mathrm{g}$ for $2 \mathrm{~h}$ at $4{ }^{\circ} \mathrm{C}$ (Rotor SW $32 \mathrm{Ti}$, Beckman Coulter, Brea, USA) (29). Pellets were resuspended in either $400 \mu \mathrm{L}$ phosphate buffered saline (PBS, Gibco PBS tablets without calcium, magnesium and phenol red) or, in case of RO EVs, in $500 \mu \mathrm{L}$ cell culture supernatant. Vesicles were purified by size exclusion chromatography, using a $30 \mathrm{~mL}$ (SBSr073 OMVs) or a $10 \mathrm{~mL}$ (RO EVs) sepharose CL-2B (GE Life Science, United Kingdom) column, collecting $1 \mathrm{~mL}$ fractions with PBS as elution buffer.

\subsection{Physico-chemical characterisation of EVs and OMVs}

Nanoparticle Tracking Analysis (NTA LM-10, Malvern, Malvern, United Kingdom) was used to determine particle concentrations and their hydrodynamic diameter (30). Samples were diluted up to 1000 fold in order to have a concentration of 10 to 100 particles per frame. A $30 \mathrm{~s}$ video at a camera 
level of 14 to 15 was recorded 3 times before the particle concentration was calculated by NanoSight 3.3 software with a detection threshold of 5 . A bicinchoninic assay kit (Sigma Aldrich) was used to quantify protein concentrations of each sample in duplicates, according to the manufacturer's specifications before and after heat treatment. To quantify the total protein content in vesicles, $25 \mu \mathrm{L}$ of RIPA buffer ( $50 \mathrm{mM}$ Tric- $\mathrm{HCl}, 150 \mathrm{mM} \mathrm{NaCl}, 0,5 \%$ deoxycholic acid, 1\% NP-40, 0,1\% sodiumdodecyl-sulfate) were incubated with $75 \mu \mathrm{L}$ of sample for $5 \mathrm{~min}$ before another bicinchoninic assay was performed.

\subsection{Heat testing}

The two SEC fractions with the highest particle concentration were pooled (final volume $2 \mathrm{~mL}$ ), transferred to glass containers, airtight sealed with caps and used for heat experiments. Samples were incubated in an incubator (Memmert UN 75, Schwabach, Germany) with a constant temperature of $37^{\circ} \mathrm{C}, 50^{\circ} \mathrm{C}, 70^{\circ} \mathrm{C}$ or $100^{\circ} \mathrm{C}$. After $1 \mathrm{~h}, 6 \mathrm{~h}$ and $24 \mathrm{~h}$ evaporated water was measured by weight difference, replaced and samples were used for further experiments. To autoclave vesicles, they were injected into brown glass containers with rubber plugs and sealed with metal caps (Zscheile \& Klinger $\mathrm{GmbH}$, Hamburg, Germany) and heated up to $121^{\circ} \mathrm{C}$ for $20 \mathrm{~min}$ at 2 bar. The temperature of a water control with the same volume was used. According to the European Pharmacopoeia, this method is one of the recommended methods for sterilisation (31). To test sterility, $100 \mu \mathrm{L}$ of autoclaved samples were incubated on lysogeny broth agar plates (Sigma Aldrich) for 4 days at $37^{\circ} \mathrm{C}$.

\subsection{Electron microscopy}

To perform cryogen electron cryomicroscopy, vesicles were concentrated using centrifugal filters (Ultracel YM - 30) until one-hundredth of volume was left. Three microliters of this solution was placed onto a holey carbon film (type S147-4, Plano, Wetzlar, Germany) and plotted for $2 \mathrm{~s}$ with a Gatan ((Pleasanton, CA, US) cryoplunger model CP3, before plunging into liquid ethane at $T=108 \mathrm{~K}$. Under liquid nitrogen, vesicles were transferred to a Gatan model 914 cryo-TEM sample holder. At $T$ = $100 \mathrm{~K}$ samples were imaged via bright field TEM (JEM-2100 LaB6, Jeol, Akishima, Tokio, Japan) under low-dose conditions.

\subsection{FACS analysis of THP-1 with vesicles}

OMVs and EVs were stained with $2 \mu \mathrm{L}$ of Dil (Vybrant Dil Cell-labelling solution $1 \mathrm{mM}$ ) for $15 \mathrm{~min}$ at $37^{\circ} \mathrm{C}$. A size exclusion chromatography with sepharose $\mathrm{CL}-2 \mathrm{~B}$ was performed to remove nonincorporated dye. Fluorescence intensity $\left(\lambda_{E x} / \lambda_{E m} 490 / 570 \mathrm{~nm}\right)$ was measured for each sample. The fraction with the highest intensity was used for further experiments. It is important to mention, that autoclaved samples had to be centrifuged for $2.5 \mathrm{~min}$ at 9,500 $\times \mathrm{g}$ in order to remove dye aggregates induced by heat and pressure. THP-1 (DSMZ, ACC16, Braunschweig, Germany) were seeded into 48 well plates with a density of 200,000 cells per well. THP-1 were stimulated with $7.5 \mathrm{ng} / \mathrm{mL}$ phorbol 12-myristate 13-acetate (PMA) (Sigma Aldrich) for $24 \mathrm{~h}$, to stimulate the differentiation to macrophage like dTHP-1. Afterwards cells were incubated with $100 \mu \mathrm{L}$ of each vesicle sample for 24 $h$, resulting in a ratio $2.5 \times 10^{5} \mathrm{RO} E V s$ and $1 \times 10^{6} \mathrm{SBSr} 073 \mathrm{OMV}$ ser cell. Two washing steps with PBS were carried out before cells were incubated with accutase solution (Sigma Aldrich) for $20 \mathrm{~min}$ at RT to detach the cells. Four wells were pooled to perform one flow cytometry (FACS) (LSRFortessa X20, BD) analysis. Cells incubated with $100 \mu \mathrm{L}$ PBS served as control. A red laser at $561 \mathrm{~nm}$ (PE phycoerythrin) was used to detect Dil labelling. Ten thousand events per sample acquired by BD FACSDiva 8.0.2, were analysed with FlowJo software version 7.6.5.

\subsection{Confocal imaging}


Stimulated THP-1 (see 2.8.) with a density of 200,000 cells per well, were incubated with $100 \mu \mathrm{L}$ of each Dil labelled EV or OMV sample in an 8 well chamber plate (SPL Life Science) for $24 \mathrm{~h}$. After removing the supernatant, cells were stained with fluorescein labelled wheat germ agglutinin (Vector laboratories) for $15 \mathrm{~min}$ at $37^{\circ} \mathrm{C}$. Subsequently, cells were fixed with $3.7 \%(\mathrm{v} / \mathrm{v})$ paraformaldehyde for $20 \mathrm{~min}$ at room temperature (RT). Nucleus staining was performed using a $1 \mu \mathrm{g} / \mathrm{mL} 4^{\prime}, 6-$ Diamidino-2-phenylindole dihydrochloride (DAPI) (Sigma Aldrich) solution (32). For confocal imaging (Leica TCS SB8) a $488 \mathrm{~nm}$ laser was used to visualise fluorescein, a $405 \mathrm{~nm}$ laser for DAPI and a 561 $\mathrm{nm}$ laser for Dil. Leica Application Suite $\mathrm{X}$ software was used to process the images.

\subsection{Statistical analysis}

All data is reported in mean $(x)$ and standard deviation (SD), where $n$ indicates the number of independent experiments. Statistical analysis was performed by SigmaPlot 14.0 using One-way ANOVA , followed by a Tukey post-hoc test, to compare the different groups. Significant $p$-values were stated as $*$ for $p<0.05,{ }^{* *}$ for $p<0.01$ or with the exact $p$-value.

\section{Results and Discussion}

\subsection{Heat-induced physico-chemical alteration of vesicles}

In this work, we analysed the heat stability of two different types of vesicles, EVs derived from B lymphoblastoid RO cells and OMVs derived from the myxobacterial strain SBSr073. For this, the vesicles were isolated, purified and incubated at $37^{\circ} \mathrm{C}, 50^{\circ} \mathrm{C}, 70^{\circ} \mathrm{C}$ and $100^{\circ} \mathrm{C}$ for $1 \mathrm{~h}, 6 \mathrm{~h}$ and $24 \mathrm{~h}$. The size of EVs and $\mathrm{OMVs}$ remained constant at $37^{\circ} \mathrm{C}$, even after $24 \mathrm{~h}$. Yet, at higher temperatures of $50^{\circ} \mathrm{C}, 70^{\circ} \mathrm{C}$ and $100^{\circ} \mathrm{C}$ small changes were detected (Fig. 1 a,d). The particle concentration of RO EVs decreased the higher and longer the samples were incubated. The most drastically change was detected at $100^{\circ} \mathrm{C}$, when particle concentrations decreased almost tenfold (Fig. 1 b). SBSr073 OMVs also showed a strong particle concentration decrease after $24 \mathrm{~h}$ at $100^{\circ} \mathrm{C}$ with a remaining $36 \%$ (Fig. $1 \mathrm{e})$. Contributing to this, the size distribution of vesicles treated at $37^{\circ} \mathrm{C}$ for $24 \mathrm{~h}$ showed similar trends compared to their controls (Fig. 2 a,c), whereas the $100^{\circ} \mathrm{C}$ samples showed stronger variations (Fig. $\mathbf{2} \mathbf{b}$, $\mathbf{d}$ ). If one looks at the protein concentration, here again, high temperatures und longer incubations times resulted in physico-chemical alteration. Especially RO EVs showed an increase of ca. $140 \%$ of protein concentration after $24 \mathrm{~h}$ at $100^{\circ} \mathrm{C}$ (Fig. $1 \mathrm{c}$ ). In contrast, the protein concentration of SBSr073 samples remained relatively constant, even at high temperatures. We hypothesise, that the decrease of the particle concentration is due to a disruption of the vesicles themselves, leading to a release of encapsulated proteins and thus an increase of protein concentration. The higher the temperature, the less stable the vesicles were and the leakier these nanostructures became. Nevertheless, for both, particle and protein concentration, RO EVs altered more drastically compared to SBSr073 OMVs, suggesting a higher physico-chemical stability of bacteria derived vesicles. Contributing to this effect is the common environment both types of vesicles can be found in. As the origin of RO EVs is the human body, which is maintained at $37^{\circ} \mathrm{C}$, they are more likely stable at $37^{\circ} \mathrm{C}$. SBSr073 OMVs, however, are derived from myxobacteria, a gram-negative population that has been adapted to various environments, from the south pole and tropical rainforests to deserts (27). In order to survive, one of their communication tools, their OMVs need to be stable in those harsh conditions. It is therefore likely, that the OMVs are more stable than the EVs. 
a)

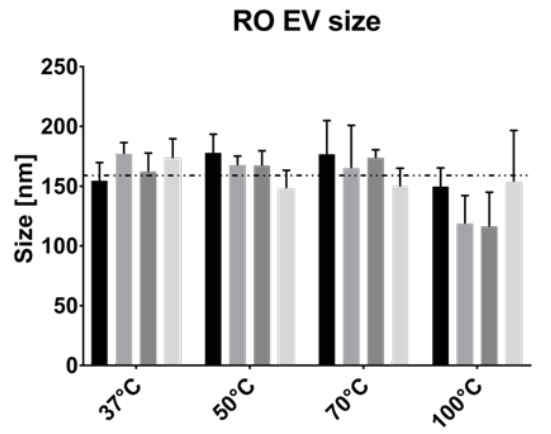

b)

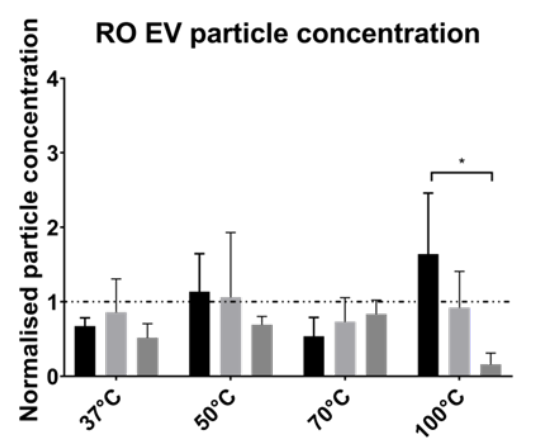

c)

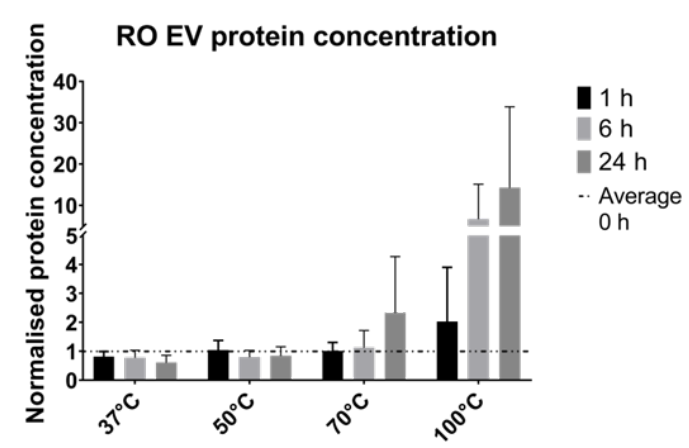

d)

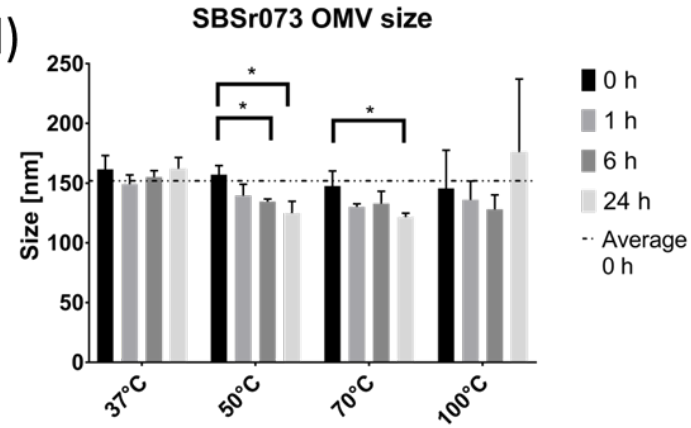

e)

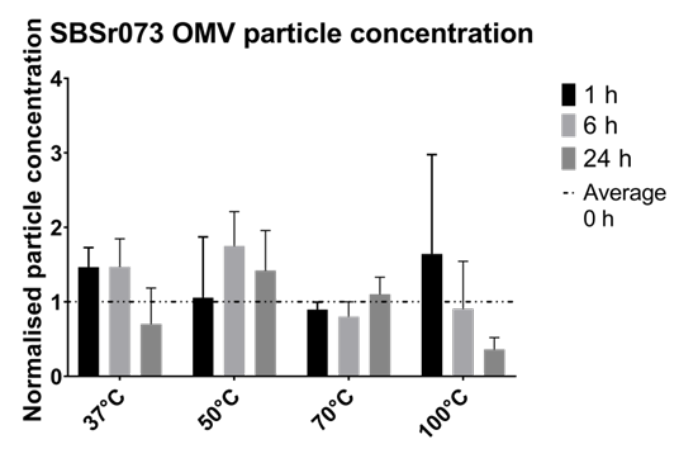

f)

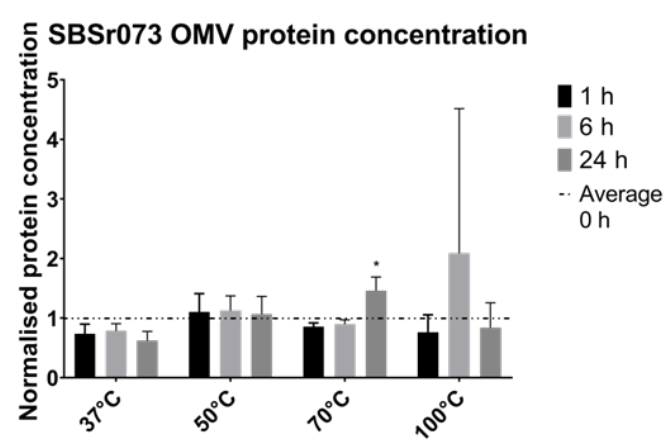

Fig 1 Physico-chemical alteration after incubation at $37^{\circ} \mathrm{C}, 50^{\circ} \mathrm{C}, 70^{\circ} \mathrm{C}, 100^{\circ} \mathrm{C}$ for $1 \mathrm{~h}, 6 \mathrm{~h}$ and $24 \mathrm{~h}$. a) RO EV size distribution before and after $24 \mathrm{~h}$ at $37^{\circ} \mathrm{C}$ b) RO EV size distribution before and after $24 \mathrm{~h}$ at $100{ }^{\circ} \mathrm{C} \mathrm{C}$ ) RO EV normalised particle concentration measured by NTA d) RO EV normalised protein concentration determined via BCA e) SBSr073 OMV distribution before and after $24 \mathrm{~h}$ at $37^{\circ} \mathrm{C}$ f) SBSr073 OMV size distribution before and after $24 \mathrm{~h}$ at $100{ }^{\circ} \mathrm{Cg}$ ) SBSr073 OMV normalised particle concentration h) SBSr073 OMV normalised protein concentration. Mean $\pm S D, n=3, * p<0.05$ (ANOVA followed by Tukey post-hoc test). Samples were normalised to particle and protein concentrations before the heat treatment. The dashed line indicates the average value of all samples at time point $0 \mathrm{~h}$. 
a)

RO EV size distribution $37^{\circ} \mathrm{C}$

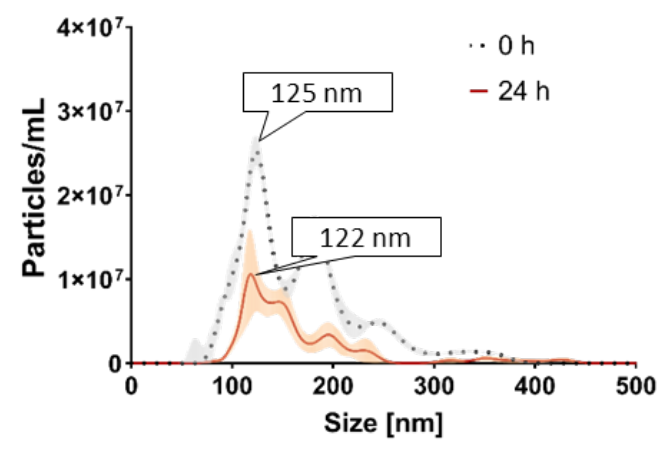

b)

RO EV size distribution $100^{\circ} \mathrm{C}$

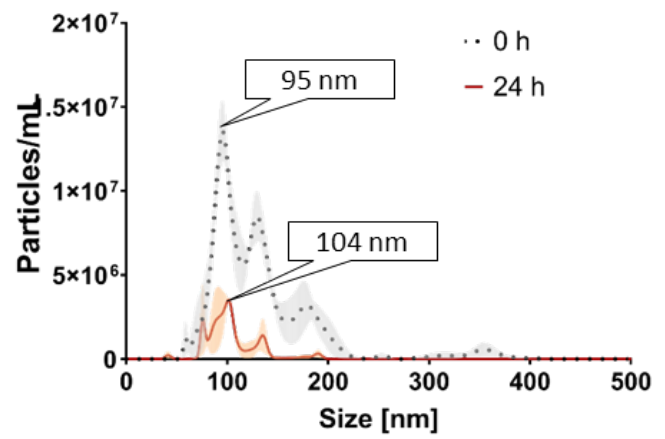

c)

SBSr073 OMV size distribution $37^{\circ} \mathrm{C}$

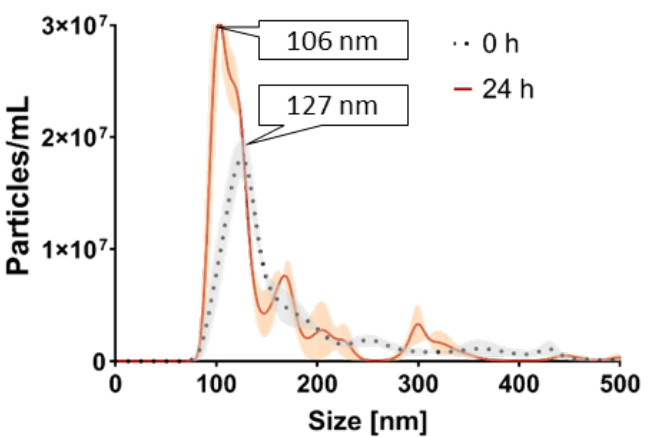

d)

SBSr073 OMV size distribution $100^{\circ} \mathrm{C}$

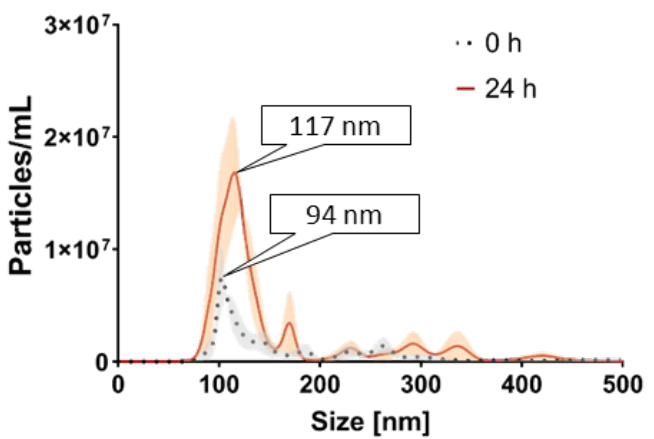

Fig 2 Representative size distribution before and after incubation at $37^{\circ} \mathrm{C}, 100^{\circ} \mathrm{C}$ for $24 \mathrm{~h}$. a) RO EV size distribution after $24 \mathrm{~h}$ at $37^{\circ} \mathrm{C}$ b) RO EV size distribution after $24 \mathrm{~h}$ at $100^{\circ} \mathrm{C}$ c) SBSr073 OMV size distribution after $24 \mathrm{~h} 37^{\circ} \mathrm{C}$ d) SBSr073 $\mathrm{OMV}$ size distribution after $24 \mathrm{~h}$ at $100^{\circ} \mathrm{C}$.

\subsection{Impact of autoclaving on vesicles}

Autoclaved samples showed comparable results to samples incubated at $100^{\circ} \mathrm{C}$. As seen in Figure 3, particle concentrations decreased while protein concentrations increased. The mean size increased slightly, and the size distribution became broader (Fig. $\mathbf{3}$ a, b). However, here again, the release of proteins of OMV samples was not as strong as the protein release of EVs (Fig. $\mathbf{3} \mathbf{c}, \mathbf{f}$ ). 
a)

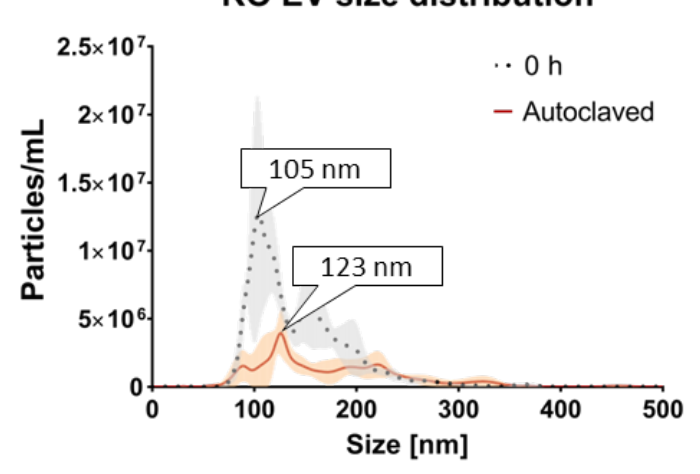

b)

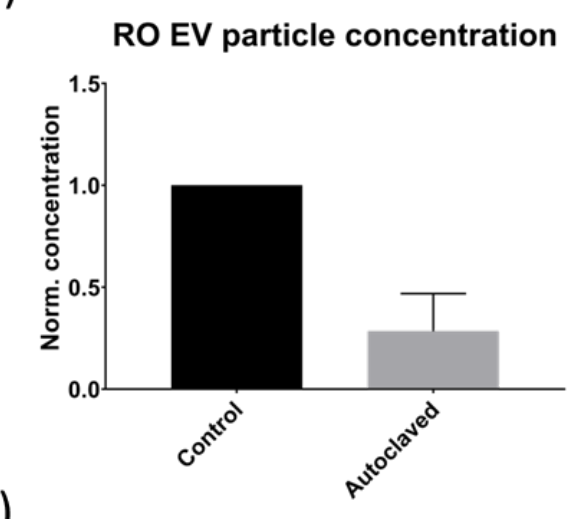

c)

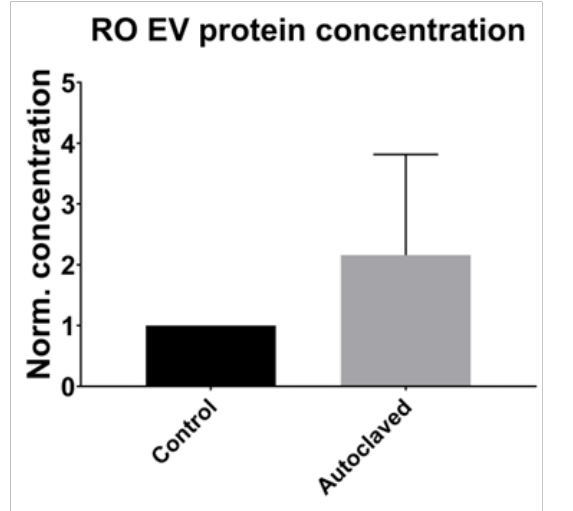

d)

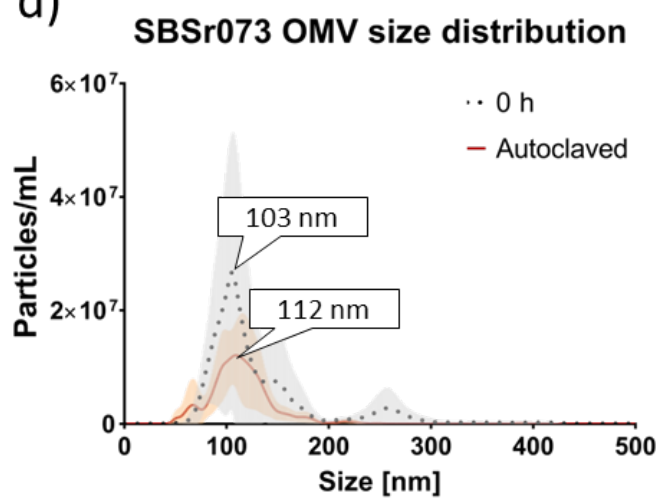

e)

SBSr073 OMV particle concentration

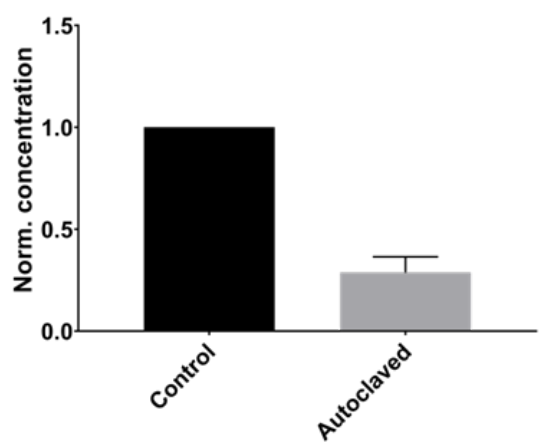

f) SBSr073 OMV protein concentration

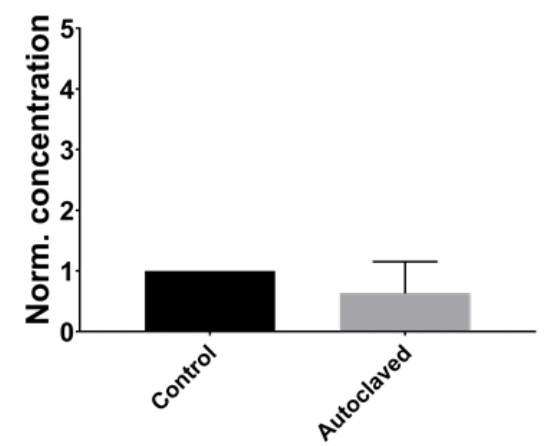

Fig 3 Physico-chemical alteration of RO EVs and SBSr073 OMVs after autoclaving. a) RO EV size distribution b) RO EV normalised particle concentration c) RO EV normalised protein concentration d) SBSr073 size distribution e) SBSr073 OMV normalised particle concentration f) SBSr073 OMV normalised protein concentration. Samples were normalised to particle and protein concentrations before autoclaving. Mean $\pm S D, n=3$

The alteration of the morphology of the vesicles due to the physico-chemical changes were also investigated by cryogenic electron microscopy (cryo-EM). By using cryo-EM we also wanted to verify the bulk size measurements determined by NTA. As shown in Figure 4 the lipid bilayer of the vesicles was clearly visible and intact (white arrows). Sizes determined by cryo-EM indicated smaller diameters compared to data collected by NTA. Indeed, NTA utilises Brownian motion to calculate the hydrodynamic diameter of particles and has a detection limit of $10 \mathrm{~nm}$ with low sensitivity (33). This may lead to enlarged particle sizes compared to cryo-EM imaging, where samples are most likely visualised in their native state. As purifying with a size exclusion step diluted samples, we concentrated them using centrifugal filters and compared them with resuspended pellets after ultracentrifugation. We noticed that sufficient concentrations of vesicles are crucial in order to visualise them and that results conducted by NTA often leads to an overestimation of sample 
concentration $(33,34)$. Unpurified vesicles showed debris and other artefacts that were also coprecipitated (Fig. $\mathbf{3}$ a, f). Subsequently, size exclusion chromatography was applied to obtain vesicles, which were then analysed by cryo-EM. With cryo-EM imaging techniques we were able to analyse single vesicles and showed that they were intact, do not form aggregates and no artefacts during the heat-treatment were formed (Fig. 4 c,d and h, i).
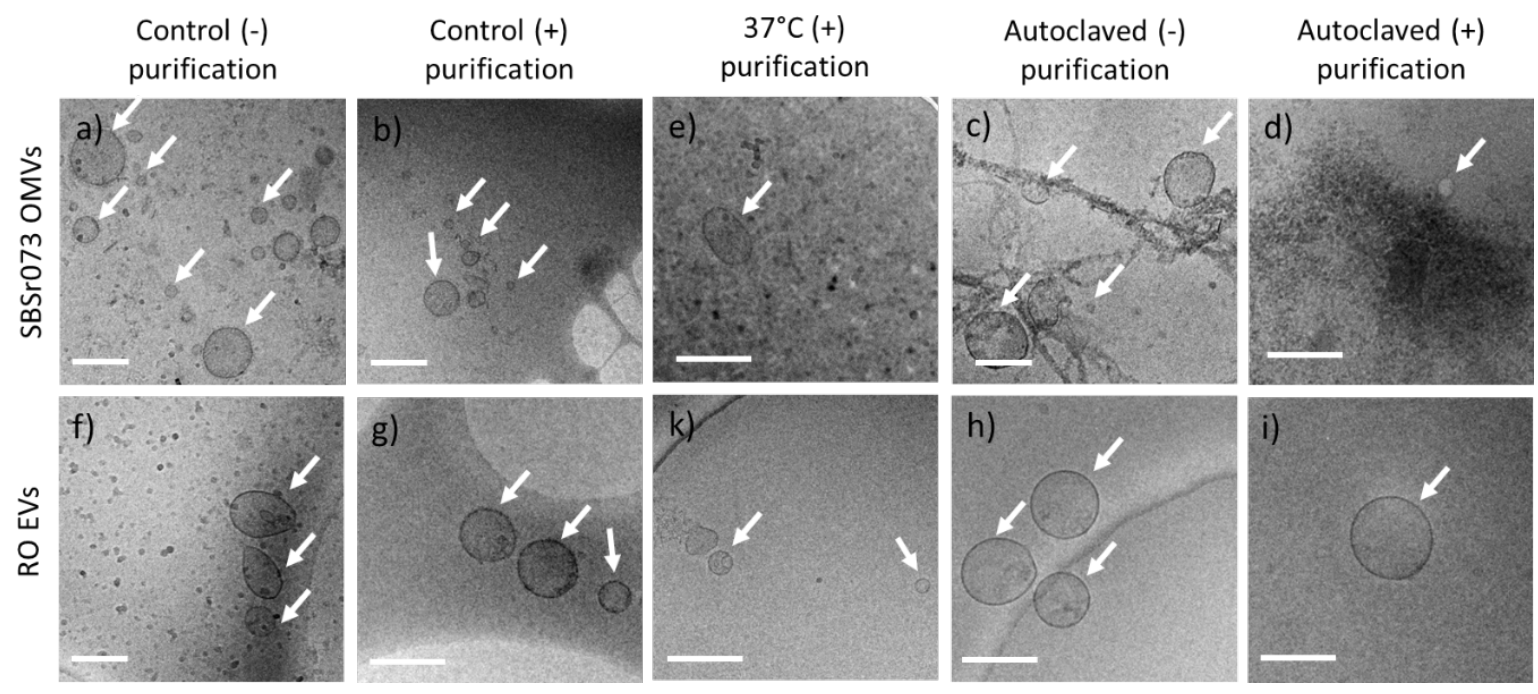

Fig 4 Cryo electron microscopy images of control and heat-treated SBSr073 OMVs and RO EVs. a) and b) SBSr073 OMVs without and with purification via SEC c) and d) respectively autoclaved SBSr073 OMVs without and with purification e) SBSr073 OMVs incubated at $37^{\circ} \mathrm{C}$ for $24 \mathrm{~h}$ and purified f) and g) RO EV without and with purification via SEC h) and i) respectively autoclaved RO EVs without and with purification k) RO EVs incubation at $37^{\circ} \mathrm{C}$ for $24 \mathrm{~h}$ and purified. Representative micrographs; arrows indicate presence of EVs and OMVs; scale bars are $0.2 \mu \mathrm{m}$.

\subsection{Uptake of heat-treated vesicles in cells analysed by FACS and confocal microscopy}

Next, we assessed, whether the observed physico-chemical alterations also influenced the biological behaviour of vesicles. We incubated heat-treated vesicles with stimulated macrophage-like dTHP-1 for $24 \mathrm{~h}$ and studied their uptake. An incubation period of $24 \mathrm{~h}$ was necessary to ensure vesicles had adequate time to interact with the cells. After this incubation period, fluorescence positive cells were analysed by flow cytometry (Fig. 5). A co-localization of labelled vesicles and cells lead to a shift to higher signal intensities of the red phycoerythrin (PE) ( $\lambda$ em $561 \mathrm{~nm}$ ) laser compared to dTHP-1 cells alone, indicating vesicle uptake (Fig. $5 \mathrm{a}, \mathrm{b}$ ). When samples were incubated at $37^{\circ} \mathrm{C}$ for $24 \mathrm{~h}$, interaction with dTHP-1 cells was comparable to non-heat-treated controls. Interestingly, autoclaved EVs were still substantially taken up by macrophages with at least $50 \%$ of Dil positive THP-1 cells, whereas autoclaved OMVs resulted in even $70 \%$ of positive cells (Fig. 5 c, d). Control experiments using Dil in PBS and purification by SEC did not show any positive signal during FACS measurements (Fig. S4 a, b). Our results show that cellular uptake of vesicles does not only depend on the particle concentration itself. Additionally, we suggest that the heat treatment did not significantly interfere with the amount of vesicles taken up. As we did not normalise the samples after the heat treatment in terms of particle concentration, still a high amount of vesicles was interacting with the macrophages even though the particle concentration decreased after autoclaving (Fig. $\mathbf{2}$ b, e and Fig. $5 \mathrm{c}, \mathrm{d})$. 

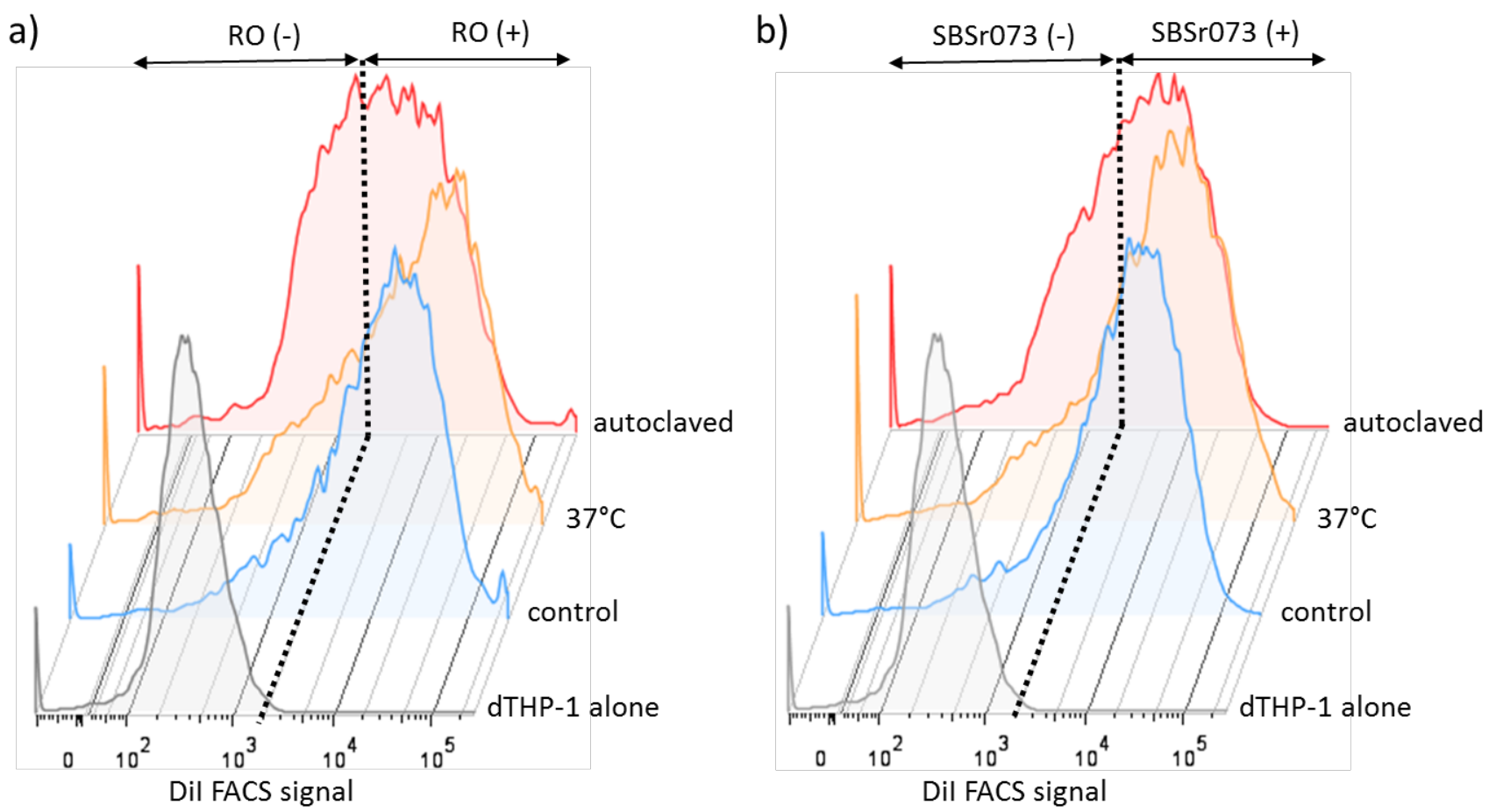

c)

RO EVs

d)

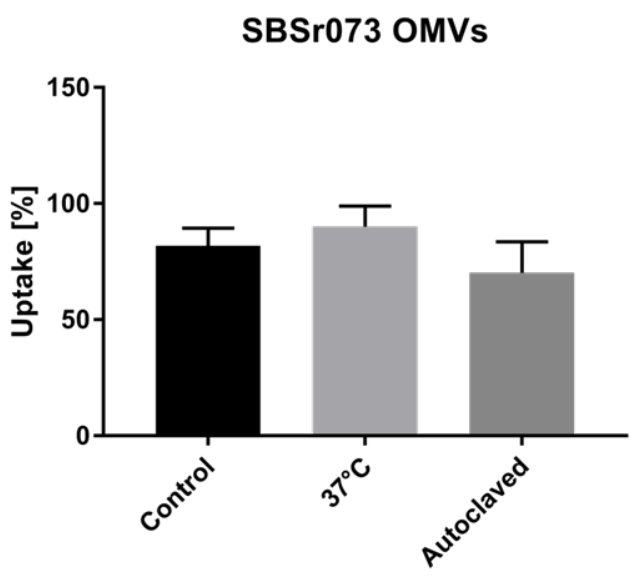

Fig 5 Interaction of RO EVs and SBSr073 OMVs with dTHP-1 upon heat treatment at $37^{\circ} \mathrm{C}$ for $24 \mathrm{~h}$ and autoclaving and analysed by FACS a) Representative signal shift of dTHP-1 without (-) or with (+) RO EV treatment (non-treated RO EVs: blue line, RO EVs incubated at $37^{\circ} \mathrm{C}$ for $24 \mathrm{~h}$ : orange line, RO EVs autoclaved: red line) b) Representative signal shift of dTHP-1 without (-) or with (+)SBSr073 OMV treatment (non-treated SBSr073 OMVs: blue line, SBSr073 OMVs incubated at $37^{\circ} \mathrm{C}$ for $24 \mathrm{~h}$ : orange line, SBSr073 OMVs autoclaved: red line) c) Uptake in percentage induced by different heat-treated RO EVs in dTHP-1 measured via FACS. Mean \pm SD, $n=3-4$ d) Uptake in percentage induced by different heat-treated SBSr073 OMVs in dTHP-1 measured via FACS. Mean \pm SD, $n=3-4$.

Confocal microscopy was further used to better understand vesicle interaction with dTHP-1 cells and to show individual cell uptake. We wanted to visualise the vesicle-cell interaction of single cells and obtain complementary information to the FACS data by assessing differences between heat-treated and non-heat-treated EVs and OMVs in presence of macrophages. 


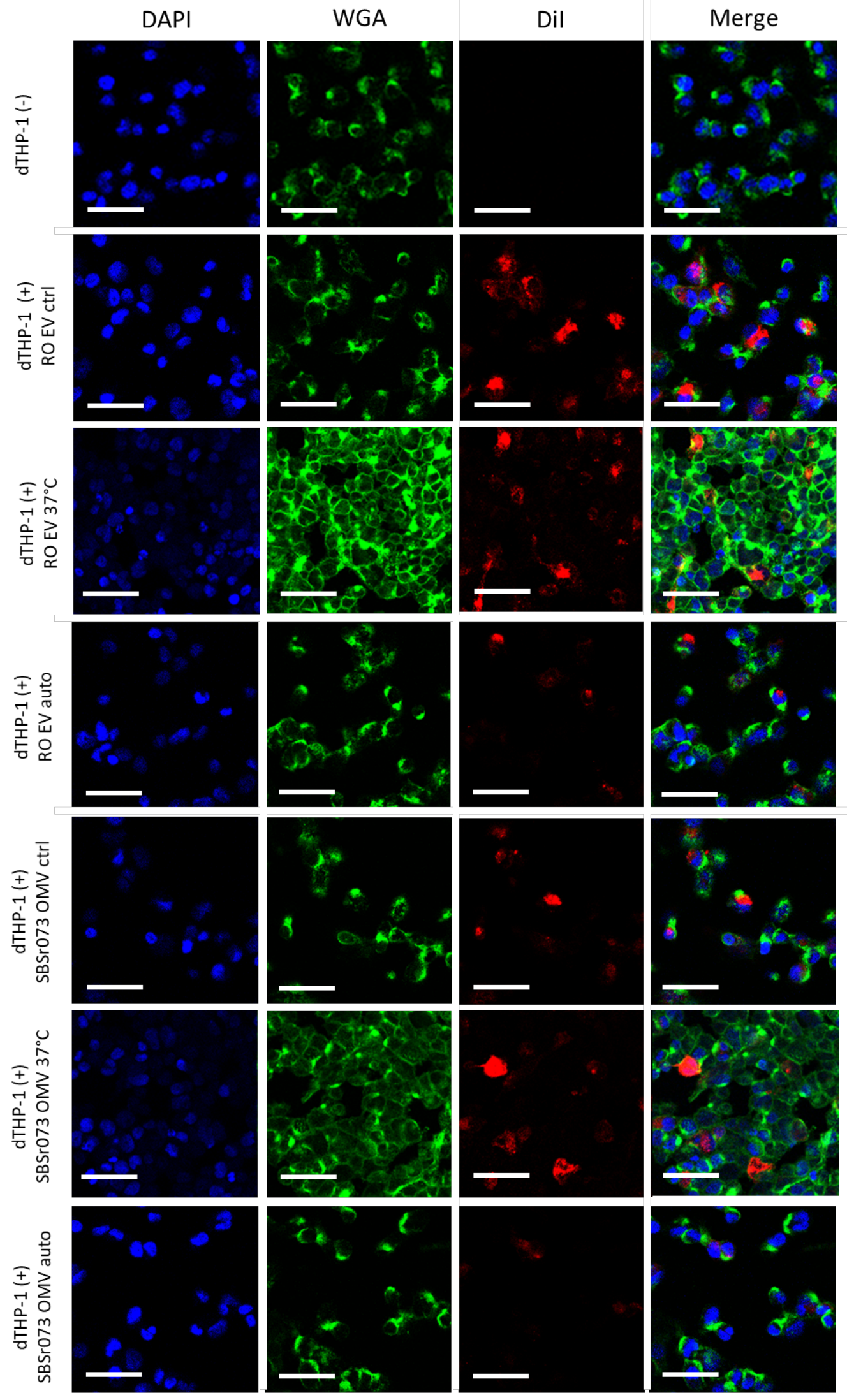

Fig 6 Confocal imaging of dTHP-1 incubated with RO EVs and SBSr073 OMVs. Cells were incubated with Dil (red) labeled EVs or OMVs for $24 \mathrm{~h}$. Nuclei were stained with DAPI (blue), while whole cell staining was undertaken using fluorescein labelled wheat germ agglutinin (green). dTHP-1 cells treated with PBS were used as negative controls. DAPI was excited using a $405 \mathrm{~nm}$ laser, a $488 \mathrm{~nm}$ laser for WGA and a $561 \mathrm{~nm}$ laser for Dil. Representative micrographs; scale bar represents $50 \mu \mathrm{m}$. 
As seen in Figure 6, cells treated only with PBS did not show any positive signal at $561 \mathrm{~nm}$ emission (i.e., laser used for Dil detection). Controls and vesicles incubated at $37{ }^{\circ} \mathrm{C}$ showed, comparably to FACS data, similar Dil fluorescence intensities within the dTHP-1. On the contrary, cells treated with autoclaved vesicles showed a lower signal in individual cells. In contrast to FACS data, here the reduction of the particle concentration after autoclaving also resulted in a lower fluorescence intensity. Here, quantitative differences were visualised by confocal microscopy, whereas FACS was not able to detect these differences, as only Dil positive cells were measured. Overall, our data showed a surprisingly inherent stability of EVs and OMVs even when treated at higher temperatures. Nevertheless, it is still important to assess thermal stability of each vesicle type individually, using different techniques and methods.

\section{Conclusion}

In this work, we investigated the impact of heat on the stability of model EVs and OMVs derived from human cells and non-pathogenic bacteria. We could show that these vesicles were physicochemically at stable at $37^{\circ} \mathrm{C}$ for $24 \mathrm{~h}$. Surprisingly, vesicles derived from non-pathogenic bacteria also show higher tolerance to hot temperatures, even up to $100^{\circ} \mathrm{C}$ compared to cell derived vesicles. Cryo-EM imaging additionally revealed the vesicles' morphology after heat impact and revealed no differences or artefacts. FACS and confocal analysis furthermore emphasises these results, indicating a high amount of uptake of control vesicles as well as low temperature treated vesicles.

Our results create a sound basis for advanced evaluation of EVs, for example, heat stability of drug loaded vesicles and the possible protection of thermally instable compounds encapsulated into vesicles, such as proteins. Such evaluation would be important for an EV formulation by spray drying or functionalisation for oral delivery (15). Additional information regarding cytotoxicity and impact on cell viability of possible heat induced by-products would be interesting to further understand the heat stability of EVs and OMVs.

\section{Acknowledgements}

This work was supported by the NanoMatFutur Junior Research programme form the Federal Ministry of Education and Research, Germany (grant number 13XP6039A). We thank Olga Hartwig with helping to establish a FACS method and Annette Boese for her support with confocal microscopy.

\section{Author contributions}

A.K. conducted all experiments on physico-chemical stability of OMVs and EVs. E.S. cultured RO cells and SBSr073 bacteria, conducted all functional experiments by FACS and confocal microscopy and wrote the manuscript text together with G.F. M.K. recorded cryo-electron microscopy images. G.F. conceived the study and supervised the project. All authors analysed the data and reviewed the manuscript. 


\section{References}

1. Chatterjee SN, Das J. Electron Microscopic Observations on the Excretion of Cell-wall Material by Vibrio cholerae. Microbiology. 1967;49(1):1-11.

2. Pan B-T, Johnstone RM. Fate of the transferrin receptor during maturation of sheep reticulocytes in vitro: Selective externalization of the receptor. Cell. 1983;33(3):967-78.

3. Mathieu M, Martin-Jaular L, Lavieu G, Théry C. Specificities of secretion and uptake of exosomes and other extracellular vesicles for cell-to-cell communication. Nature Cell Biology. 2019;21(1):9-17.

4. Fuhrmann G, Herrmann IK, Stevens MM. Cell-derived vesicles for drug therapy and diagnostics: Opportunities and challenges. Nano Today. 2015;10(3):397-409.

5. Yu Y-j, Wang X-h, Fan G-C. Versatile effects of bacterium-released membrane vesicles on mammalian cells and infectious/inflammatory diseases. Acta Pharmacologica Sinica. 2017;39:514.

6. Schwechheimer C, Kuehn MJ. Outer-membrane vesicles from Gram-negative bacteria: biogenesis and functions. Nature Reviews Microbiology. 2015;13:605.

7. Kuehn AJMaMJ. Outer Membrane Vesicles. 2005.

8. Lener T, Gimona M, Aigner L, Börger V, Buzas E, Camussi G, et al. Applying extracellular vesicles based therapeutics in clinical trials - an ISEV position paper. Journal of Extracellular Vesicles. 2015;4:10.3402/jev.v4.30087.

9. clinicaltrail.gov. Allogenic Mesenchymal Stem Cell Derived Exosome in Patients With Acute Ischemic Stroke [Clinical Trail]. [updated 31.12.18. Available from:

https://clinicaltrials.gov/ct2/show/NCT03384433.

10. Gujrati V, Kim S, Kim S-H, Min JJ, Choy HE, Kim SC, et al. Bioengineered Bacterial Outer Membrane Vesicles as Cell-Specific Drug-Delivery Vehicles for Cancer Therapy. ACS Nano. 2014;8(2):1525-37.

11. Schulz E, Goes A, Garcia R, Panter F, Koch M, Müller R, et al. Biocompatible bacteria-derived vesicles show inherent antimicrobial activity. Journal of Controlled Release. 2018;290:46-55.

12. Pinheiro A, Silva AM, Teixeira JH, Gonçalves RM, Almeida MI, Barbosa MA, et al. Extracellular vesicles: intelligent delivery strategies for therapeutic applications. Journal of Controlled Release. 2018;289:56-69.

13. Fuhrmann G, Chandrawati R, Parmar PA, Keane TJ, Maynard SA, Bertazzo S, et al. Engineering Extracellular Vesicles with the Tools of Enzyme Prodrug Therapy. Advanced materials (Deerfield Beach, Fla). 2018;30(15):e1706616-e.

14. Lórincz ÁM, Timár Cl, Marosvári KA, Veres DS, Otrokocsi L, Kittel Á, et al. Effect of storage on physical and functional properties of extracellular vesicles derived from neutrophilic granulocytes. Journal of Extracellular Vesicles. 2014;3(1):25465.

15. Frank J, Richter M, de Rossi C, Lehr C-M, Fuhrmann K, Fuhrmann G. Extracellular vesicles protect glucuronidase model enzymes during freeze-drying. Scientific Reports. 2018;8(1):12377.

16. Charoenviriyakul C, Takahashi Y, Nishikawa M, Takakura Y. Preservation of exosomes at room temperature using lyophilization. International Journal of Pharmaceutics. 2018;553(1):1-7.

17. Park SJ, Jeon H, Yoo S-M, Lee M-S. The effect of storage temperature on the biological activity of extracellular vesicles for the complement system. In Vitro Cellular \& Developmental Biology -

Animal. 2018;54(6):423-9.

18. Cheng $\mathrm{Y}$, Zeng $\mathrm{Q}$, Han $\mathrm{Q}$, Xia W. Effect of $\mathrm{pH}$, temperature and freezing-thawing on quantity changes and cellular uptake of exosomes. Protein \& Cell. 2019;10(4):295-9.

19. Goldbach $\mathrm{P}$, Brochart $\mathrm{H}$, Stamm, A. Spray-Drying of liposomes for a Pulmonary Administration. I. Chemical Stability of Phospholipids. Drug Development and Industrial Pharmacy. 1993;19(19):2611-22.

20. Bamberger D, Hobernik D, Konhäuser M, Bros M, Wich PR. Surface Modification of Polysaccharide-Based Nanoparticles with PEG and Dextran and the Effects on Immune Cell Binding and Stimulatory Characteristics. Molecular Pharmaceutics. 2017;14(12):4403-16.

21. Skotland T, Sandvig K, Llorente A. Lipids in exosomes: Current knowledge and the way forward. Progress in Lipid Research. 2017;66:30-41. 
22. Ruigrok RWH, Martin SR, Wharton SA, Skehel JJ, Bayley PM, Wiley DC. Conformational changes in the hemagglutinin of influenza virus which accompany heat-induced fusion of virus with liposomes. Virology. 1986;155(2):484-97.

23. Vergauwen G, Dhondt B, Van Deun J, De Smedt E, Berx G, Timmerman E, et al. Confounding factors of ultrafiltration and protein analysis in extracellular vesicle research. Scientific Reports. 2017;7(1):2704.

24. Martin R. Hadam RD, Gerd Dammer, Claudia Derau, Dietrich Niethammer. Expression of MHC-Antigens in MHC-Class-II-Deficiency. Jaak Vossen CG, editor1986. 89-96 p.

25. Préval Cd, Hadam MR, Mach B. Regulation of Genes for HLA Class II Antigens in Cell Lines from Patients with Severe Combined Immunodeficiency. New England Journal of Medicine. 1988;318(20):1295-300.

26. Müller KJWaaR. Myxobacterial secondary metabolites: bioactivities and modes-of-action. Nat Prod Rep. 2010.

27. Reichenbach H. The ecology of the myxobacteria. Environmental Microbiology. 1999;1(1):15-

21.

28. Fuhrmann G, Serio A, Mazo M, Nair R, Stevens MM. Active loading into extracellular vesicles significantly improves the cellular uptake and photodynamic effect of porphyrins. Journal of Controlled Release. 2015;205:35-44.

29. Shao H, Im H, Castro CM, Breakefield X, Weissleder R, Lee H. New Technologies for Analysis of Extracellular Vesicles. Chemical Reviews. 2018;118(4):1917-50.

30. Gardiner C, Ferreira YJ, Dragovic RA, Redman CWG, Sargent IL. Extracellular vesicle sizing and enumeration by nanoparticle tracking analysis. Journal of Extracellular Vesicles. 2013;2:10.3402/jev.v2i0.19671.

31. Agency EM. Guideline on the sterilisation of the medicinal product, active substance, excipient and primary container. 2019.

32. Menina S, Eisenbeis J, Kamal MAM, Koch M, Bischoff M, Gordon S, et al. Bioinspired Liposomes for Oral Delivery of Colistin to Combat Intracellular Infections by Salmonella enterica. Advanced Healthcare Materials.0(0):1900564.

33. Bachurski D, Schuldner M, Nguyen P-H, Malz A, Reiners KS, Grenzi PC, et al. Extracellular vesicle measurements with nanoparticle tracking analysis - An accuracy and repeatability comparison between NanoSight NS300 and ZetaView. Journal of extracellular vesicles. 2019;8(1):1596016- .

34. Arraud N, Linares R, Tan S, Gounou C, Pasquet J-M, Mornet S, et al. Extracellular vesicles from blood plasma: determination of their morphology, size, phenotype and concentration. Journal of Thrombosis and Haemostasis. 2014;12(5):614-27. 